\title{
HYPOPHOSPHATEMIA SECONDARY TO REFEEDING SYNDROME IN A SYSTEMIC LUPUS ERYTHEMATOSUS PATIENT: THE IMPORTANCE OF PHOSPHORUS IN A NON-OSTEOMETABOLIC DISORDER
}

Rodrigo Vidaurre (HCFMUSP, São Paulo, SP, Brasil), Nestor José de Souza Barreto Neto (HCFMUSP, São Paulo, SP, Brasil), Aline Carolina Capellato Dias (HCFMUSP, São Paulo, SP, Brasil), Matheus Santos Rodrigues Silva (HCFMUSP, São Paulo, SP, Brasil), Lissiane Karine Noronha Guedes (HCFMUSP, São Paulo, SP, Brasil), Luciana Parente Costa Seguro (HCFMUSP, São Paulo, SP, Brasil), Rosa Maria Rodrigues Pereira (HCFMUSP, São Paulo, SP, Brasil)

\section{BACKGROUND}

Refeeding syndrome (RS) consists of metabolic disturbances that occur due to the re-introduction of carbohydrates to a patient who had a long period of fasting and/or carbo-restricted diet. Refeeding causes sudden shifts in the metabolism of the malnourished person, from intense catabolysm to anabolysm, resulting in life-threatening electrolyte and vitamin disorders. Hypophosphatemy is the greatest hallmark of RS, as a result of increased cell up uptake for ATP synthesis, in an organism with phosphorus depletion. Also hypokalemia, hipocalcemia, hypomagnesemia and tiamine deficit can occur.

\section{CASE REPORT}

27-year-old, female, with systemic lupus erythematosus (SLE) diagnosis since 17 (with previous renal, hematologic, cutaneous and articular manifestations), non-adherent to treatment was admitted with a history of fever (two peaks), noninvasive diarrhea and genital bleeding for one week. She referred one episode of generalized tonic-clonic seizure one day before hospitalization. Her admission weight was 39 $\mathrm{kg}$ and the BMI was $14 \mathrm{~kg} / \mathrm{m} 2$; she had signs of malnutrition, alopecia and painful oral ulcers. No hepatosplenomegaly. Her diet was compromised by hyporexia and pain caused by the ulcers. Cranial CT was normal, as the cerebrospinal fluid analysis. Laboratory tests showed anemia $(\mathrm{Hb}-5.6 \mathrm{xx})$, neutropenia (100xxx), thrombocytopenia (9000xxx), high ferritin levels (1873xxx), low reticulocytes, hypoalbuminemia and hypocomplementenemia. Lactate dehydrogenase and haptoglobin levels were within the normal range. She received methylprednisolone $80 \mathrm{mg} /$ day, blood transfusion, large-spectrum antibiotic therapy (for febrile neutropenia) and intravenous immunoglobulin, with no improvement in cytopenias. After ruling out infection, she received pulses of methylprednisolone (1g/day, 3 days) with gradual improvement of clinical and laboratory alterations. Food acceptance and dysphagia improved, and she started a non-restricted diet, gaining $3 \mathrm{~kg}$. Routine laboratory tests showed severe hypophosphatemia $(1,0 \mathrm{xxx})$ and hypokalemia $(2,8 \mathrm{xxx})$. There was no evidence of drug adverse event or renal or intestinal loss. In the context of re-introducing diet after some days of malnutrition and nutrient deprivation, RS diagnostic was made. Calories offer was reduced, with posterior gradual progression. Electrolytes and vitamins were replaced, especially thiamine and vitamin D.

\section{CONCLUSION}

The authors claim attention to the importance of phosphate dosage in the context of malnutrition. Besides hyporexia, the oral lesions, caused by SLE activity, were an important factor that contributed to malnutrition. Of note, refeeding syndrome is a potential fatal condition that can be prevented by checking electrolytes, especially phosphate, of high risk patients (low weight, weight loss and/or little or no nutritional intake for more than 10 days). 